\title{
Power Supply of Video Monitoring Device Used for the Cable Operation, Maintenance and Management
}

\author{
Zhang xilin $^{1, a}$, Pang dan ${ }^{1, b}$, Shao weiyan ${ }^{1, c}$ Wang zhenhao ${ }^{2, d}$ \\ ${ }^{1}$ State Grid Jilin Electric Power Company Limited Changchun Power Supply Company, Changchun, Jilin Changchun 130021, China \\ ${ }^{2}$ Northeast Dianli University, Jilin Jilin 132012, China
}

\begin{abstract}
The power supply is used for operation, maintenance and management of the cable line in engineering, the cable circuit applying power supply device could carry on energy by induction, we have designed the AC-DC altering circuit, energy discharge circuit and protection circuit and so on, the reliability of the device is tested by field application.
\end{abstract}

\section{Introduction}

In the project of operating ,maintaining and managing cable line, there are installed a lot of $3 \mathrm{G}$ wireless video devices, many devices are installed on the base pole in the open space outdoors, the voltage level is of $66 \mathrm{kV}$ or more, we cannot directly get power, currently, we use the battery power and have to regularly go to the field to replace the battery, it bring a lot of inconvenience to the work, the problem of supplying power is the key, according to the actual situation, the technical issue can be effectively solved by the method of carrying on energy by induction in the cable near the installation video devices.

The load current of the cable line is very complex, and the electric current is changed to a great extent. In order to guarantee the power supply, the power supply designed has the characteristics as follow. (1)Current in the condition of low current, try to ensure supplying power; (2) When the current is large current or the lightning surge current, such as short circuit fault state, it have to give the sufficient protection to power; (3) Within the normal range of the current it can provide stable output, Short-term power continuous power supply, and can satisfy the instantaneous power supply; (4) The low thermal consumption and stable operation for a long time.

\section{Constitution}

The power supply is consisted of a well-formed electric CT, rectifier filter circuit, DC/DC conversion circuit, voltage protection circuit and energy discharge circuit, transient protection, energy storage circuit. The principle structure diagram is shown in Figure 1.

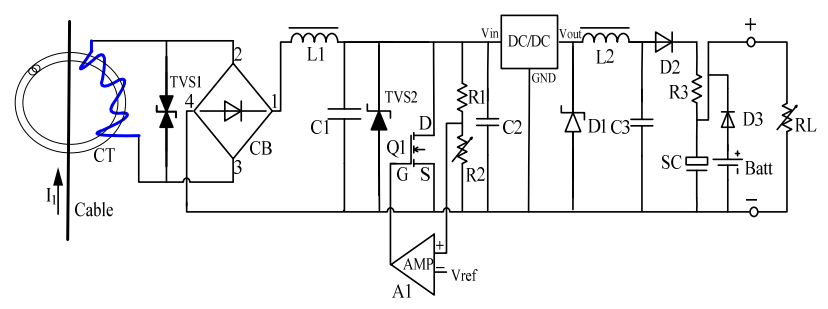

Figure 1. Principle diagram of power plant

\subsection{Rectifier Circuit and Filter Circuit}

Out of the line on induction electric potential is an AC voltage, while, electronic circuit need dc voltage, so the voltage from the core coil is required to be rectified. The device selects a bridge type rectifier. When the current is large, the two current sensing is not too big, but the pulse peak can reach up to 100 volts, so the rectifier circuit should have a high voltage value, therefore, the DB107 rectifier bridge, the pressure value reached $1000 \mathrm{~V}$, can meet the actual requirements.

In order to improve the pulse voltage, the filter circuit is required to be added to the rectifier and filter circuit is used for filtering the ripple of the output voltage of the rectifier. Considering the complex filter circuit can increase the power consumption of the circuit and improve the starting current, the system chose the LC filter circuit, the rectifier filter circuit is shown in Figure 2, $\mathrm{L} 1$ is $100 \mathrm{mH}, \mathrm{C} 1$ is $1000 \mathrm{~F}$.

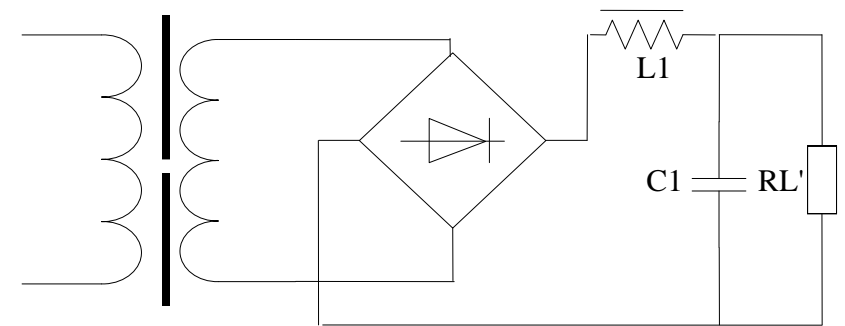

Figure 2. Bridge type rectifier circuit structure diagram

\subsection{DC-DC Conversion Circuit}

Due to the wide variation range of current, the induced voltage is rectified and filtered, and the wide range of DC voltage will be obtained. After a DC-DC module, a high quality $5 \mathrm{~V}$ DC voltage can be obtained to meet the power supply needs of the monitoring device. Power DCDC module selects AMC34063A, voltage input range is $3-40 \mathrm{~V}$, output voltage $5 \mathrm{~V}$, maximum output current $1.5 \mathrm{~A}$, about $2 \mathrm{~mA}$ of the quiescent current, with high conversion efficiency, high conversion efficiency is conducive to further reduce the starting current, improve the output power.

The power consumption of the DC-DC converter is relatively large, and the power consumption of the power supply circuit can be reduced without the same power 
consumption. And the key to reduce the power consumption of the power supply circuit is to reduce the power consumption of AMC34063A, DC-DC has a smaller power consumption, it is very good to meet the requirements of power supply.

\subsection{Voltage Protection and Energy Discharge Circuit}

After the rectifier filter, the voltage of the DC-DC module is increased with the increase of current, and the voltage is also high. In order to protect the DC-DC module, the voltage must be limited in the range of the module technology, and the voltage protection and energy release circuit shown in Figure 3. When voltage Udc greater than $10 \mathrm{~V}$, the partial pressure of the voltage on the resistor R2 is higher than the reference voltage Vref, voltage comparatorLM393 output high level and large power MOS tube conduction, excess energy by large power MOS tube discharged; when the Udc is lower, circuit does not work, so it will not affect the normal working under the power supply starting current and small current.

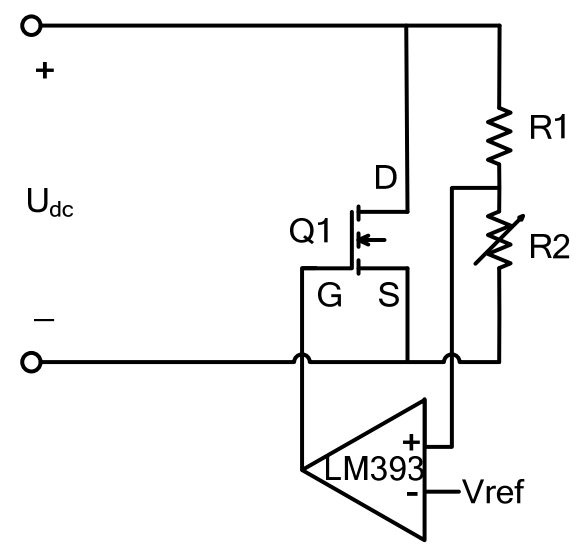

Figure 3. Transient protection of voltage protection and energy drain circuit

When there is a lightning stroke or line appears short circuit current, the core will produce a very high impact voltage, which is very bad for the back end of the circuit. In order to protect the rear end line, a bipolar TVS pipe is connected at both ends of the rectifier bridge to limit the impact voltage output from the induction coil. TVS diode select the P6KE68CA, so that the rectifier bridge input AC voltage peak - peak value maintained within the $100 \mathrm{~V}$, it can ensure that the follow-up circuit is not affected by the impact of energy damage.

\subsection{Energy Storage Circuit}

Using super capacitor SC as energy storage element, it could solve the problem of fast charging and discharging and low temperature working environment, the new concept of energy storage device between traditional storage battery and traditional static capacitor. Compared with conventional capacitors, it has the characteristics of large capacity, high energy density, wide operating temperature range and long service life. It is suitable for the complicated outdoor environment of winter in the north, and it can improve the load adaptability (especially the large power fluctuation load).

Cable grounding current monitoring device data transmission use wireless communication mode, data transceiver instantaneous power is larger, reaching about $1 \mathrm{~A}$, while the standby mode of operation is only $10-20$ $\mathrm{mA}$. Added to the super capacitor energy storage, it have solved the difficulty of transient power supply, in order to increase the reliability of power supply, we add the Israeli TADIRAN lithium battery Batt after the super capacitor, in normal circumstances, the lithium battery is not for the device. Israel TADIRAN lithium battery can be used in the environment of the temperature between 55 and +85 , and it is of a high energy density and low self-discharge. Under normal temperature, the shelf life of it can be more than 10 years. So, we choose the rated capacity of 2Ah Israel TADIRAN lithium batteries, standard voltage $3.6 \mathrm{~V}$.

The power supply takes into account all kinds of situations, and can be stable and reliable in the case of low temperature and large current changes.

\section{Transient Protection}

Transient Voltage Suppresser is called TVS for short, it is a high-performance protection device with diode form. Voltage characteristics of TVS are shown as Figure 4, forward characteristics of which are as same as ordinary diode and the reverse characteristics are typical PN junction avalanche devices. In the figure, $\mathrm{U}_{\mathrm{br}}$ is standard voltage of TVS, which also known as the breakdown voltage, it refers to the voltage across when the device enters the avalanche conduction process under an ambient temperature of $25{ }^{\circ} \mathrm{C}$, when the device under the action of a transient peak pulse current, the current flowing through TVS rises from original reverse leakage current Id to Ir, voltage presented by its poles rises from rated reverse voltage turn-off voltage Urm to the breakdown voltage Ubr, TVS breakdown. With the advent of peak pulse current, the current flowing through TVS reaches peak pulse current Ipp. Voltage in its polars is clamped to a predetermined maximum clamping voltage. As the pulse current decays exponentially, TVS bipolar voltage declining, finally, back to the initial state. This is the surge pulsed power and the whole process protecting electronic components by TVS suppression. 


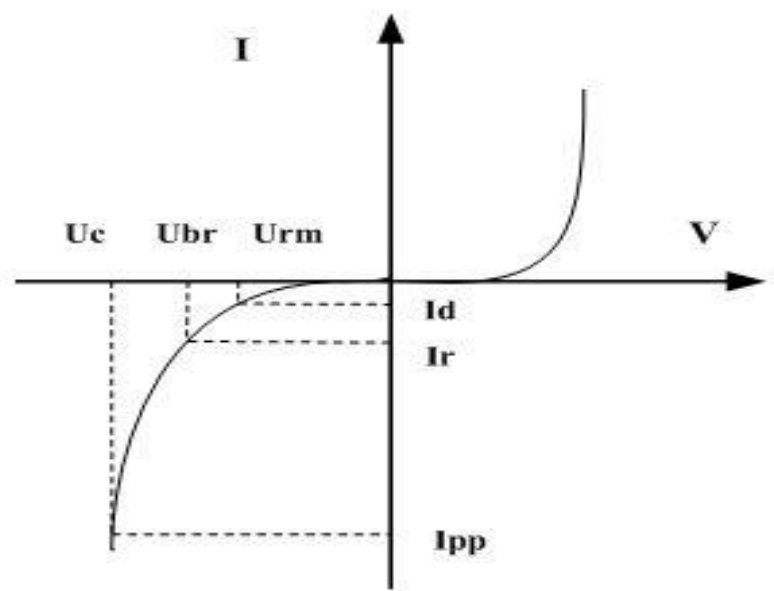

Figure 4. Voltage characteristics of TVS

When TVS diode poles shocked by reverse transient high-energy, which can make a high impedance to a low impedance between two poles at a speed order of 10-12 seconds, absorbing up to several kilowatts of surge power, so box-bit voltage between the poles will be made a predetermined value, which have an effective protection on precision components of electronic circuits from a variety of surge pulse damage. Because of its fast response time, high transient power, low leakage current, small breakdown voltage deviation, box-bit voltage is easier to control, no damage limit, small size and so on, TVS has been widely used in computer systems, communications equipment, power supply , household appliances and other fields. When there is lightning or high short-circuit current occurs, then the core will induce a high impulse voltage, which is extremely detrimental to the back-end circuit; in order to protect the back-end circuit, a bipolar TVS tube is connected across the coil in front of the rectifier bridge to limit the impulse voltage from the induction coil. P6KE68CA is used in TVS diodes, so that the rectifier bridge input AC voltage peak is maintained at less than $100 \mathrm{~V}$ to protect the follow-up circuit from impulse energy damage.

\section{The prototype experiment}

In this paper, the main parameters of designed power supply prototype, outer diameter of microcrystalline alloys core is $90 \mathrm{~mm}$, the inside diameter of which is $50 \mathrm{~mm}$, and the height is $30 \mathrm{~mm}$, The coil number of turns is 210; rated current of Power transistor $10 \mathrm{~A}$, using two $2.5 \mathrm{~V} 10 \mathrm{~F}$ super capacitors in series to achieve $5 \mathrm{~V}$.

Design requirements of power supply prototype are: Starting current is $6 \mathrm{~A}$,under the start current, the output power should greater than $80 \mathrm{~mW}$,so it can power load(normal power is about $60 \mathrm{~mW}$, instant power can up to $1 \mathrm{~W})$ stability; the temperature of draw-out power coil under long term operation should be kept under $20^{\circ} \mathrm{C}$.

Results based on test with load are shown in Table.1, DC-DC module can output stable $5 \mathrm{~V}$ voltage under each current, coil and circuit and the load device have stable operation .
Table 1. Test results of power supply prototype with load

\begin{tabular}{cc}
\hline Bus current & $\begin{array}{c}\text { Output voltage of } \\
\text { DC-DC module }\end{array}$ \\
\hline $6 \mathrm{~A}$ & $4.95 \mathrm{~V}$ \\
$10 \mathrm{~A}$ & $4.97 \mathrm{~V}$ \\
$20 \mathrm{~A}$ & $4.97 \mathrm{~V}$ \\
$50 \mathrm{~A}$ & $4.98 \mathrm{~V}$ \\
$100 \mathrm{~A}$ & $4.98 \mathrm{~V}$ \\
$200 \mathrm{~A}$ & $4.98 \mathrm{~V}$ \\
$600 \mathrm{~A}$ & $4.98 \mathrm{~V}$
\end{tabular}

Practical tests show: the transceiver high-power supply super capacitor first data of the prototype power supply shows its voltage drop is about $0.02 \mathrm{~V}$, after a short time the voltage has increased to the equilibrium voltage, the load device tested is stable. In the case of a short power outage of transmission line, energy storage of super capacitor can also keep the testing device standing more than 10 minutes. When starting current is $6 \mathrm{~A}$, the terminal voltage curve of the super capacitor with the above-mentioned test load is shown in Figure 5, there is data transmission and high-power supply at the 5th second, 26th second and 31th second.

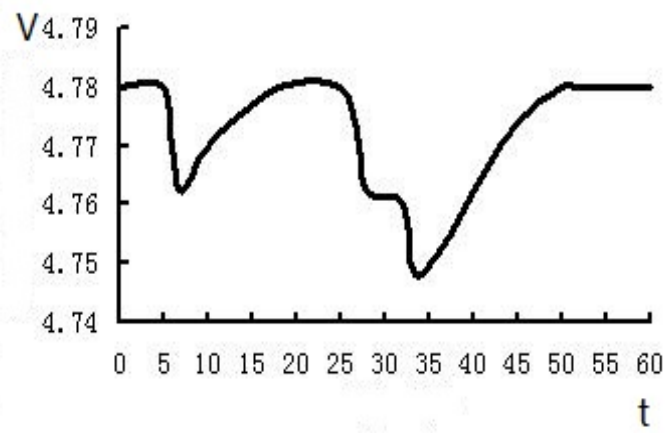

Figure 5. Terminal voltage curve of super capacitor

\section{Summary}

Laboratory and field tests show that the power supply is ensured when the power supply is small, and the electric current can be protected by the power supply when the current is large or when the impact current is high. The normal current range can provide stable output, short duration power supply and power supply to meet the instantaneous high power supply. Power supply is used to the video monitoring device of cable operation , maintenance and management, and the circuit design principle is given and apply to the actual project, with the characteristics of that the starting current is small, the wiring is simple, it has achieved good results.

\section{References}

[1] LI Xianzhi, DU Lin, CHEN Weigen, et al, A novel scheme of draw-out power supply utilized in transmission line state monitoring, Automation of Electric Power Systems, 32(1): 76-80(2008)

[2] WANG Zan, ZONG Fei, WANG Wei, et al, Development of power supply in high voltage side of 
transmission lines, Advances of Power System \& Hydroelectric Engineering, 26(6): 23-27(2010)

[3] LIU Yadong, SHENG Gehao, WANG Youjia, et al, Current transformer draw-out power supply design based on power controlled method, Automation of Electric Power Systems, 34(3): 70-74(2010)

[4] LIN Jie, LIU Gang, ZHANG Ming, Impact analysis for the air-gap width of draw-out power supply coil, High Voltage Apparatus, 48(12): 75-79(2012)

[5] GUO Linyun, YIN Xianggen, YAN Xinrong, et al, Research of improving power efficiency for intelligent device self-power supply utilized in power distribution network, Proceedings of the CSEE, 29(S1): 217-221(2009)

[6] WU Jintao, SHENG Gehao, ZENG Yi, et al, Design and development of power supply for transmission line online monitor device, Electric Engineering, 2: 33-35(2009) 